\title{
Front Matter: Volume 9042
}

, "Front Matter: Volume 9042," Proc. SPIE 9042, 2013 International Conference on Optical Instruments and Technology: Optical Systems and Modern Optoelectronic Instruments, 904201 (31 December 2013); doi: $10.1117 / 12.2056660$

SDIE Event: International Conference on Optical Instruments and Technology (OIT2013), 2013, Beijing, China 


\title{
2013 International Conference on Optical Instruments and Technology \\ Optical Systems and Modern Optoelectronic Instruments
}

\author{
Yongtian Wang \\ Xiaocong Yuan \\ Yunlong Sheng \\ Kimio Tatsuno \\ Editors
}

17-19 November 2013

Beijing, China

Sponsored by

CIS-China Instrument and Control Society (China)

SPIE

Cooperating Organizations

Opto-Electronic-Mechanic Technology and System Integration Chapter, CIS (China) • Committee on Optoelectronic Technology, COS (China) • Optical Instrument Chapter, CIS (China) • Beijing Institute of Technology (China) • Tianjin University (China) • Zhejiang University (China) • Tsinghua University (China) • Nankai University (China) • Capital Normal University (China) - Nanjing University (China) - Shanghai Jiaotong University (China) • Beijing University of Posts and Telecommunications (China) - Chongqing University (China) - University of Shanghai for Science and Technology (China) • Beijing Hamamatsu Photon Techniques Inc. (China) • Instrument Society of America (United States) • Institute of Measurement and Control (United Kingdom) • Hong Kong Institution of Engineers (China) • The Society of Measurement and Control (Japan)

Published by

SPIE

Volume 9042 
The papers included in this volume were part of the technical conference cited on the cover and title page. Papers were selected and subject to review by the editors and conference program committee. Some conference presentations may not be available for publication. The papers published in these proceedings reflect the work and thoughts of the authors and are published herein as submitted. The publisher is not responsible for the validity of the information or for any outcomes resulting from reliance thereon.

Please use the following format to cite material from this book:

Author(s), "Title of Paper," in 2013 International Conference on Optical Instruments and Technology: Optical Systems and Modern Optoelectronic Instruments, edited by Yongtian Wang, Xiaocong Yuan, Yunlong Sheng, Kimio Tatsuno, Proceedings of SPIE Vol. 9042 (SPIE, Bellingham, WA, 2013) Article CID Number.

ISSN: 0277-786X

ISBN: 9780819499608

Published by

SPIE

P.O. Box 10, Bellingham, Washington 98227-0010 USA

Telephone +1 3606763290 (Pacific Time) · Fax +1 3606471445

SPIE.org

Copyright (c) 2013, Society of Photo-Optical Instrumentation Engineers.

Copying of material in this book for internal or personal use, or for the internal or personal use of specific clients, beyond the fair use provisions granted by the U.S. Copyright Law is authorized by SPIE subject to payment of copying fees. The Transactional Reporting Service base fee for this volume is $\$ 18.00$ per article (or portion thereof), which should be paid directly to the Copyright Clearance Center (CCC), 222 Rosewood Drive, Danvers, MA 01923. Payment may also be made electronically through CCC Online at copyright.com. Other copying for republication, resale, advertising or promotion, or any form of systematic or multiple reproduction of any material in this book is prohibited except with permission in writing from the publisher. The CCC fee code is 0277-786X/13/\$18.00.

Printed in the United States of America.

Publication of record for individual papers is online in the SPIE Digital Library.

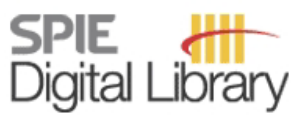

SPIEDigitallibrary.org

Paper Numbering: Proceedings of SPIE follow an e-First publication model, with papers published first online and then in print and on CD-ROM. Papers are published as they are submitted and meet publication criteria. A unique, consistent, permanent citation identifier (CID) number is assigned to each article at the time of the first publication. Utilization of CIDs allows articles to be fully citable as soon as they are published online, and connects the same identifier to all online, print, and electronic versions of the publication. SPIE uses a six-digit CID article numbering system in which:

- The first four digits correspond to the SPIE volume number.

- The last two digits indicate publication order within the volume using a Base 36 numbering

system employing both numerals and letters. These two-number sets start with 00, 01, 02, 03, 04, $05,06,07,08,09,0 A, 0 B \ldots$. 0Z, followed by 10-1Z, 20-2Z, etc.

The CID Number appears on each page of the manuscript. The complete citation is used on the first page, and an abbreviated version on subsequent pages. Numbers in the index correspond to the last two digits of the six-digit CID Number. 


\title{
Contents
}

\author{
ix Symposium Committee \\ xi Conference Committee \\ xiii Introduction
}

\section{SESSION 1 OPTICAL SYSTEMS AND INSTRUMENTS}

904202 Micro-optics in advanced optical metrology (Invited Paper) [9042-60]

M. Józwik, Warsaw Univ. of Technology (Poland)

904203 Sub-millimeter servo system for sample positioning based on thresholding of defocused laser spot [9042-76]

Z. Wang, L. Cao, E. Zhang, G. Jin, Tsinghua Univ. (China)

\section{SESSION 2 ABERRATION ANALYSIS AND CORRECTION FOR IMAGING SYSTEMS}

904204 A technique for extracting and analyzing the polarization aberration of hyper-numerical aperture image optics (Invited Paper) [9042-85]

Y. Li, X. Guo, X. Liu, L. Liu, Beijing Institute of Technology (China)

904205 Towards standardized assessment of endoscope optical performance: geometric distortion (Invited Paper) [9042-90]

Q. Wang, U.S. Food and Drug Administration (United States); V. N. Desai, U.S. Food and Drug Administration (United States) and Univ. of Maryland, College Park (United States); Y. Z. Ngo, U.S. Food and Drug Administration (United States) and Virginia Commonwealth Univ. (United States); W.-C. Cheng, J. Pfefer, U.S. Food and Drug Administration (United States)

904206 Design method on the stabilized zoom lens design of focal-length-variable elements [9042-33]

Q. Hao, Beijing Institute of Technology (China); X. Cheng, K. Du, Tsinghua Univ. (China)

904207 Comprehensive discussion of the projection relations to restrain aberrations caused by change of object distance [9042-13]

L. Ren, M. Shibuya, S. Nakadate, Tokyo Polytechnic Univ. (Japan)

904208 Automatic aberrations compensation for thin object in off-axis digital holographic microscopy [9042-54]

Y. Liu, Xi'an Jiaotong Univ. (China) and Xi'an Univ. of Technology (China); Z. Wang, J. Li, J. Huang, J. Gao, Xi'an Jiaotong Univ. (China)

904209 Study on the fast optimal direction determination for missile-borne star sensor [9042-69] J. Yang, L. Kong, Beihang Univ. (China); K. Xiong, Beijing Institute of Control Engineering (China) 
9042 OA Image-based computational holography for deep 3D scene display (Invited Paper) [9042-101]

M. Yamaguchi, Tokyo Institute of Technology (Japan)

9042 OB Special-purpose computer for real-time reconstruction of holographic motion picture (Invited Paper) [9042-67]

T. Kakue, Chiba Univ. (Japan); N. Masuda, Nagaoka Univ. of Technology (Japan); Y. Endo,

R. Hirayama, N. Okada, T. Shimobaba, T. Ito, Chiba Univ. (Japan)

9042 OC 3D motion picture recording by parallel phase-shifting digital holographic microscopy (Invited Paper) [9042-63]

T. Tahara, Kansai Univ. (Japan); P. Xia, Kyoto Institute of Technology (Japan) and Japan Society for the Promotion of Science (Japan); T. Kakue, Chiba Univ. (Japan); Y. Awatsuji, K. Nishio, S. Ura, Kyoto Institute of Technology (Japan); T. Kubota, Kubota Holography Lab. Corp. (Japan); O. Matoba, Kobe Univ. (Japan)

9042 OD Parallel phase-shifting digital holography using LCOS-SLM (Invited Paper) [9042-62] M. Lin, K. Nitta, O. Matoba, Kobe Univ. (Japan); Y. Awatsuji, Kyoto Institute of Technology (Japan)

9042 OE Numerical study on statistical properties of speckle pattern in laser projection display based on human eye model [9042-15]

Z. Cui, A. Wang, Q. Ma, H. Ming, Univ. of Science and Technology of China (China)

\section{SESSION 4 DISPLAY SYSTEMS AND ILLUMINATION SYSTEMS}

9042 OF Liquid crystal lens array for 3D display and 3D air-touch (Invited Paper) [9042-102]

Y.-P. Huang, T.-H. Jen, Y.-C. Chang, G.-Z. Wang, P.-Y. Shieh, C.-W. Chen, L.-Y. Liao, National Chiao Tung Univ. (Taiwan, China)

9042 OG Assessment of 3D quality of experience with content analysis [9042-80]

B. Zou, Y. Liu, Y. Huang, Y. Wang, Beijing Institute of Technology (China)

$9042 \mathrm{OH} \quad$ Research of frequency modulation to amplitude modulation with multi-frequency modulation [9042-29]

Y. Zhou, Univ. of Science and Technology of China (China) and China Academy of Engineering Physics (China); S. Zhan, Y. Geng, L. Liu, China Academy of Engineering Physics (China); L. XU, H. Ming, Univ. of Science and Technology of China (China)

9042 Ol Simulation of imaging and refocusing for light field photography [9042-42] H. Huang, X. Li, Z. Cen, Zhejiang Univ. (China)

9042 0J Design of zoom system for pupil shaping of lithography tool [9042-3]

R. Fang, A. Zeng, S. Zhang, H. Huang, Shanghai Institute of Optics and Fine Mechanics (China) and Graduate Univ. of Chinese Academy of Sciences (China) 
9042 OK An integrated multispectral face recognition system (Invited Paper) [9042-30]

Y. Zheng, Alcorn State Univ. (United States)

$9042 \mathrm{OL} \quad$ High-speed holographic correlation system for video identification on the internet (Invited Paper) [9042-83]

E. Watanabe, K. Ikeda, The Univ. of Electro-Communications (Japan); K. Kodate, Photonic System Solutions Inc. (Japan)

9042 OM Error analysis of a 3D imaging system based on fringe projection technique (Invited Paper) [9042-10]

Z. Zhang, J. Dai, Hebei Univ. of Technology (China)

9042 ON High-accuracy 3D measurement system based on multi-view and structured light [9042-58] M. Li, D. Weng, Y. Li, L. Zhang, H. Zhou, Beijing Institute of Technology (China)

\section{POSTER SESSION}

904200 Control of light tunneling through electromagnetically induced transparency-like metamaterials [9042-4]

T. Feng, Xuchang Univ. (China) and Tongji Univ. (China); L. Wang, Xuchang Univ. (China); Y. Li, Tongji Univ. (China)

9042 OP Development of spectrophotometer for breast tumor diagnostic spectrometer based on virtual instruments [9042-6]

Z. Ren, Jiangxi Science and Technology Normal Univ. (China) and Nanchang Univ. (China); G. Liu, Jiangxi Science and Technology Normal Univ. (China); Y. Liu, Nanchang Univ. (China); Z. Huang, Jiangxi Science and Technology Normal Univ. (China)

9042 OQ Design on the readout electronics for the mobile direct detection Doppler wind LIDAR [9042-7]

X. Gao, F. Wen, Y. Yao, Z. Sang, G. Jin, Univ. of Science and Technology of China (China)

$9042 \mathrm{OR}$ Theoretical and numerical analysis of wavefront error caused by atmospheric turbulence through deformable mirrors [9042-11]

D. Zhang, M. Hui, Y. Zhao, L. Dong, R. Zhao, Beijing Institute of Technology (China)

9042 OS Human eye color difference threshold measurement system [9042-16]

L. Liu, T. Zhou, Beijing Institute of Technology (China)

9042 OT Optical vortex beams generated by a phase-only LC-SLM and double-slit interference analysis [9042-18]

D. Chen, J. Qi, W. Wang, J. Yang, P. Wang, Q. Zhang, H. Deng, H. Zhang, D. Sun, H. Shan, X. Ma, B. Shi, New Star Institute of Applied Technology (China)

9042 OU Off-axis illumination of lithography tool [9042-19]

H. Xing, L. Lin, Beijing Institute of Technology (China); M. Bin, Institute of Optics, Univ. of Rochester (United States) 
9042 OV Design of collimating system for LED source [9042-20]

Y. Shen, Y. Huang, X. Han, Beijing Institute of Technology (China)

9042 OW Cascade pumped random lasers with coherent emission formed by Ag-Au porous nanowires [9042-23]

Y. Wang, X. Shi, Y. Sun, R. Zheng, S. Wei, J. Shi, Z. Wang, D. Liu, Beijing Normal Univ. (China)

9042 OX Study on method of simulating Golay3 MMT by external programming [9042-24]

X. Zhu, F. Wu, Changzhou Institute of Technology (China); Q. Wu, Suzhou Univ. of Science and Technology (China); L. Qian, Soochow Univ. (China)

9042 OY The Lyman-alpha Imager onboard Solar Polar Orbit Telescope [9042-25]

B. Li, H. Li, National Space Science Ctr. (China); S. Zhou, B. Jiang, Xi'an Institute of Optics and Precision Mechanics (China)

$90420 Z$ A new method for measuring the refractive index of glass [9042-28]

W. Zhang, X. Su, Y. Yang, C. Mi, Hebei Univ. (China)

904210 Terahertz frequency spectrum characterization of coherent heterodyne time-domain spectrometer [9042-31]

J. Zhao, Beijing Institute of Technology (China) and Capital Normal Univ. (China); L. Zhang,

Y. Luo, T. Wu, C. Zhang, Capital Normal Univ. (China); Y. Zhao, Beijing Institute of

Technology (China)

$904211 \quad$ A data driven BRDF model based on Gaussian process regression [9042-32]

Z. Tian, D. Weng, J. Hao, Beijing Institute of Technology (China); Y. Zhang, China Aeronautical Radio Electronics Research Institute (China); D. Meng, Beijing Institute of Technology (China)

904212 Femtosecond digital holography based on spatial light modulator [9042-38]

X. LU, J. Li, H. Chen, Shenzhen Univ. (China)

904213 Research on the liquid crystal adaptive optics system for human retinal imaging [9042-39] L. Zhang, S. Tong, Y. Song, X. Zhao, Changchun Univ. of Science and Technology (China)

904214 A novel optimization strategy for LED street lamp designing [9042-40]

Y. Dong, Z. Cen, X. Li, W. Pang, W. Ruan, Zhejiang Univ. (China)

904215 Control system design for a double-prism scanner [9042-43]

H. Zhang, Y. Yuan, Y. Zhao, L. Su, Beihang Univ. (China)

904216 A compact high ER pulse power laser for photon-counting optical time-domain reflectometer [9042-51]

C. Zhang, X. Ding, X. Liu, G. Jin, X. Jiang, Univ. of Science and Technology of China (China)

904217 Radiation characterization analysis of pushbroom longwave infrared imaging spectrometer [9042-53]

R. Shi, Y. Chen, J. Zhou, W. Shen, Soochow Univ. (China) 
904218 The research on LED-based spectrally tunable light source for star simulator [9042-55] $X$. Zhang, Changchun Univ. of Science and Technology (China) and Jilin Technology College of Electronic Information (China); G. Zhang, J. Zhang, Changchun Univ. of Science and Technology (China)

904219 Design and manufacture of an athermalication high-speed lens with low veiling glare [9042-57]

R. Shi, Y. Ji, Z. Zhao, X. Chen, W. Song, W. Shen, Soochow Univ. (China)

$90421 \mathrm{~A}$ The optimal design method for the extended source of interferometer [9042-59]

Y. Hou, L. Li, S. Wang, Beijing Institute of Technology (China); X. Wang, China North Industries Navigation and Control Technology Research Institute (China); H. Zang, Q. Zhu, D. Li, Beijing Institute of Technology (China)

9042 1B Double-ring vortex beams generated by coaxial superposition of Laguerre-Gaussian modes [9042-68]

C. He, S. Huang, Shanghai Univ. (China)

9042 1C High precision $6.8 \mathrm{GHz}$ phase locking of coherent laser beams for optical lattice experiment [9042-73]

X. Ding, L. Sang, C. Zhang, G. Jin, X. Jiang, Univ. of Science and Technology of China (China)

9042 1D Design of a high power laser diode driver [9042-79]

W. Li, Q. Wang, L. Liu, Z. Peng, Beijing Institute of Technology (China)

9042 1E Transmitted spectral modulation of double-ring resonator using liquid crystals in terahertz range [9042-82]

H. Sun, Beijing Institute of Technology (China) and Beijing Union Univ. (China); Q. Zhou, Capital Normal Univ. (China); X. Wang, Beijing Univ. of Civil Engineering and Architecture (China); C. Li, A. WU, C. Zhang, Capital Normal Univ. (China)

9042 IF Design of optical frequency comb for sky survey astronomical spectrograph calibration [9042-84]

Y. Hu, X. Wang, Beijing Institute of Technology (China)

$90421 G \quad$ Multi-excitation Raman difference spectroscopy based on modified multi-energy constrained iterative deconvolution algorithm [9042-88]

W. Zou, Z. Cai, Soochow Univ. (China); H. Zhou, Institute of Microelectronics Equipment Co., Ltd. (China); J. Wu, Soochow Univ. (China)

$90421 \mathrm{H} \quad$ High power diode lasers reliability experiment [9042-93]

G. Lu, S. Xie, M. Hao, Y. Huang, Y. En, China Electronic Product Reliability and Environmental Testing Research Institute (China)

904211 Simulation of imaging spectrometers degraded by satellite vibrations with pseudo crosscorrelation theory [9042-100]

L. Zhang, Y. Chang, Y. Tang, Y. Nan, Q. Guo, Beijing Institute of Technology (China) 
$90421 \mathrm{~J} \quad$ Reduction of image optics dependence of resist image performance for high NA extreme Ultraviolet lithography [9042-104]

O. Chun, Y. Li, L. Liu, Beijing Institute of Technology (China)

Author Index

viii

Proc. of SPIE Vol. $9042904201-8$

Downloaded From: https://www.spiedigitallibrary.org/conference-proceedings-of-spie on 26 Apr 2023 Terms of Use: https://www.spiedigitallibrary.org/terms-of-use 


\title{
Symposium Committee
}

\author{
General Chairs \\ Songlin Zhuang, University of Shanghai for Science and Technology \\ (China) \\ William H. Arnold, ASML US, Inc. (United States) \\ Conference Cochairs \\ Yuri Chugui, New Siberia Academy of Sciences (Russian Federation) \\ Arthur Chiou, National Yang-Ming University (Taiwan, China) \\ Liwei Zhou, Beijing Institute of Technology (China) \\ Shenghua Ye, Tianjin University (China) \\ Yimo Zhang, CIS/Tianjin University (China) \\ Technical Program Chair \\ Guofan Jin, Tsinghua University (China) \\ Technical Program Cochairs \\ Jinxue Wang, Raytheon Company (United States) \\ Tiegen Liu, Tianjin University (China) \\ Local Organizing Committee Chair \\ Youhua Wu, China Instrument and Control Society (China) \\ Local Organizing Committee Cochairs \\ Guoqiang Ni, Beijing Institute of Technology (China) \\ Daoyin Yu, Tianjin University (China) \\ Yanbiao Liao, Tsinghua University (China) \\ Yulin Xi, Beijing Hamamatsu Photon Techniques Inc. (China) \\ General Secretary \\ Youhua Wu, China Instrument and Control Society (China) \\ Administrative Vice General Secretary \\ Yu-nan Sun, Beijing Institute of Technology (China)
}


Vice General Secretaries

Wei Xue, Beijing Institute of Technology (China)

Qun Hao, Beijing Institute of Technology (China)

Yuejin Zhao, Beijing Institute of Technology (China)

Qionghui Feng, University of Shanghai for Science and Technology (China)

Cunlin Zhang, Capital Normal University (China)

Local Organizing Committee

Changming Zhao, Beijing Institute of Technology (China)

Zheng You, Tsinghua University (China)

Yumei Wen, Chongqing University (China)

Hongda Chen, Institute of Semiconductors (China)

Shangzhong Jin, China Jiliang University (China)

Zhiping Zhou, Peking University (China)

Xuping Zhang, Nanjing University (China)

Libo Yuan, Harbin Engineering University (China)

Chunqing Gao, Beijing Institute of Technology (China)

Shiqiao Qin, National University of Defense Technology (China)

Tian Lan, Beijing Institute of Technology (China)

Cuiling Li, Beijing Institute of Technology (China)

Liquan Dong, Beijing Institute of Technology (China) 


\title{
Conference Committee
}

\author{
Conference Chairs
}

Yongtian Wang, Beijing Institute of Technology (China)

Xiaocong Yuan, Nankai University (China)

Yunlong Sheng, Laval University (Canada)

Kimio Tatsuno, Koga Research Institute (Japan)

Program Committee

Jiabi Chen, University of Shanghai for Science and Technology (China)

Chunlei Du, Institute of Optics and Electronics (China)

Yi-chin Fang, National Kaohsiung First University of Science and

Technology (Taiwan, China)

Qun Hao, Beijing Institute of Technology (China)

Aaron H.P. Ho, Chinese University of Hong Kong (Hong Kong, China)

Minghui Hong, National University of Singapore (Singapore)

Hong Hua, The University of Arizona (United States)

Ken Y. Hsu, National Chiao Tung University (Taiwan, China)

Tsuyoshi Konishi, Osaka University (Japan)

Irina L. Livshits, St. Petersburg State University of Information Technologies, Mechanics and Optics (Russian Federation)

Osamu Matoba, Kobe University (Japan)

Xiang Peng, Shenzhen University (China)

Jannick P. Rolland, University of Rochester (United States)

Han-Ping Shieh, National Chiao Tung University (Taiwan, China)

Jinghua Teng, Institute of Materials Research and Engineering (Singapore)

Din Ping Tsai, National Taiwan University (Taiwan, China)

Wilhelm Ulrich, Carl Zeiss AG (Germany)

Paul Urbach, Delft University of Technology (Netherlands)

Dewen Cheng, Secretary, Beijing Institute of Technology (China)

Session Chairs

1 Optical Systems and Instruments

Kimio Tatsuno, Koga Research Institute (Japan)

2 Aberration Analysis and Correction for Imaging Systems

Yongtian Wang, Beijing Institute of Technology (China)

3 Digital Holography

Juan Liu, Beijing Institute of Technology (China) 
$4 \quad$ Display Systems and Illumination Systems

Masahiro Yamaguchi, Tokyo Institute of Technology (Japan)

$5 \quad$ Image Analysis and Applications

Yunlong Sheng, Laval University (Canada) 


\section{Introduction}

Optical Systems and Modern Optoelectronic Instruments has been a subconference of OIT since its inauguration in 2008. In 2013 there were nearly 100 submissions to this sub-conference, from which 13 invited talks, 19 oral presentations and 37 posters were selected. Experts from the United States, Japan, Poland, Canada, mainland and Taiwan of China came to Beijing, attending the sub-conference and presenting their newest research results. Most of the presented papers are published in this SPIE Proceedings volume.

There were six sessions in the sub-conference, reporting recent progress on optical systems and instruments, aberration analysis and correction for imaging systems, digital holography, display systems and illumination systems, image analysis and applications, respectively.

We believe that this year's Optical Systems and Modern Optoelectronic Instruments conference was a high-quality conference, and the papers included in these proceedings are of good reference value to our fellow scientists and engineers. 
Proc. of SPIE Vol. 9042 904201-14

Downloaded From: https://www.spiedigitallibrary.org/conference-proceedings-of-spie on 26 Apr 2023 Terms of Use: https://www.spiedigitallibrary.org/terms-of-use 